\title{
MICROSTRUCTURE AND MECHANICAL PROPERTIES OF FRICTION STIR WELDED JOINTS BETWEEN COMMERCIALLY PURE COPPER AND Al 6351 ALLOY
}

\begin{abstract}
In the present study, the effect of tool rotational speed on microstructure and mechanical properties of friction stir welded joints between commercially pure copper and $6351 \mathrm{Al}$ alloy was carried out in the range of tool rotational speeds of 300-900 rpm in steps of $150 \mathrm{rpm}$ at $30 \mathrm{~mm} /$ minutes travel speed. Up to $450 \mathrm{rpm}$, the interface of the joints is free from intermetallics and $\mathrm{Al}_{4} \mathrm{Cu}_{9}$ intermetallic has been observed at the stir zone. However, $\mathrm{Al}_{4} \mathrm{Cu}_{9}$ intermetallic was observed both at the interface and the stir zone at $600 \mathrm{rpm}$. At 750 and $900 \mathrm{rpm}$ tool rotational speed, the layers of $\mathrm{AlCu}, \mathrm{Al}_{2} \mathrm{Cu}_{3}$ and $\mathrm{Al}_{4} \mathrm{Cu}_{9}$ intermetallics were observed at the interface and only $\mathrm{Al}_{4} \mathrm{Cu}_{9}$ intermetallics has been observed in the stir zone. The maximum ultimate tensile strength of $\sim 207 \mathrm{MPa}$ and yield strength of $\sim 168 \mathrm{MPa}$ along with $\sim 6.2 \%$ elongation at fracture of the joint have been obtained when processed at 450 rpm tool rotational speed.
\end{abstract}

Keywords: Friction Stir Welding; Tensile strength; Microstructure; intermetallics

\section{Introduction}

In recent years, the development of sound joints between dissimilar materials is a very important concern for many emerging applications of chemical, nuclear, aerospace, transportation, power generation, and electronics industries [1-4]. However, dissimilar materials joints by conventional fusion welding shows poor weldability arising due to the difference in chemical, mechanical, thermal properties of materials and formation of brittle intermetallic compounds at the weld interface [5-7]. Friction stir welding (FSW) has many advantages such as low processing temperature, easy work-piece preparation, no fusion defect risk, less accidental threat, cost effective(for non ferrous materials) no need of shielding gases and microstructure refinement in the welds, and has been applied widely to join metallic materials such as aluminum, magnesium and copper alloys [8]. Recently, FSW is considered to be a potential candidate to join dissimilar metals and alloys effectively, and dissimilar FSW of $\mathrm{Al} / \mathrm{Mg}, \mathrm{Al} /$ steel, $\mathrm{Al} / \mathrm{Ti}$, etc. has been studied [9-12].

Ouyang et al. [7] performed study on FSW of 6061 aluminum alloys to pure copper plates of $12.7 \mathrm{~mm}$ thick. They found that the weld nugget consists mainly $\mathrm{CuAl}_{2}, \mathrm{CuAl}$, and $\mathrm{Cu}_{9} \mathrm{Al}_{4}$, and observed difficulties in the direct FSW of 6061 aluminum alloy to copper, due to the formation of brittle intermetallics compounds. Recently, another group of researcher made an investigation to study the feasibility of friction stir welding of dissimilar lap joints of an aluminum plate to a copper plate [13].
The level of bond strength was quite low in their investigation and comparison of the fracture location with microstructure suggested that intermetallic compounds formed at the interfacial region were responsible for the low strength of the joints. Xue et al. [14] studied the effects of FSW parameters on the microstructures and properties of $\mathrm{Cu}-1060 \mathrm{Al}$ dissimilar joints, and suggested that a thin and continuous layer of intermetallic compounds was necessary to achieve sound $\mathrm{Cu}-\mathrm{Al}$ joints. Liu et al. [6] found that there were no new Al-Cu intermetallics in the $\mathrm{Cu}-5 \mathrm{~A} 06 \mathrm{Al}$ joints. Mishra et al. [1] pointed out that, the FSW of dissimilar metals, such as aluminum to copper, was still not successful in producing sound joint. Li et al. [15] reports that the FSW of pure copper/1350 aluminum alloy sheet with a thickness of $3 \mathrm{~mm}$ and achieved the tensile strength of $152 \mathrm{MPa}$ and $6.3 \%$ elongation at a rotational speed of $1000 \mathrm{rpm}$ and a traverse speed of $80 \mathrm{~mm} / \mathrm{min}$. They also observed that no intermetallic compounds were found in the weld joints. Saeid et al. [16-17] used FSW to produce the lap joints of $\mathrm{Cu}-1060 \mathrm{Al}$. When compared with the FSW process of homogeneous alloys, the material flow and microstructure evolution during FSW of dissimilar is much more complicated.

In the present study, the joining of aluminum alloy (AA6351) and commercially pure $\mathrm{Cu}$ was carried out by FSW technique using tool rotational speeds of 300 to $900 \mathrm{rpm}$ in steps of $150 \mathrm{rpm}$ with a traverse speed of $30 \mathrm{~mm} / \mathrm{minute}$ and also correlated the microstructure and tensile strength with the welding parameter of the dissimilar joints.

\footnotetext{
* DEPARTMENT OF METALLURGY AND MATERIALS ENGINEERING, INDIAN INSTITUTE OF ENGINEERING SCIENCE AND TECHNOLOGY, SHIBPUR, HOWRAH-711103, INDIA

\# Corresponding author: skundu@metal.iiests.ac.in
} 


\section{Experimental procedures}

\section{2a. Base materials}

Aluminum alloy (AlA) and commercially pure $(\mathrm{Cu})$ having thickness of $3 \mathrm{~mm}$ each was used in this study. Chemical composition and the room temperature tensile strength of the base materials are given in Table 1 and 2 .

TABLE 1

Chemical compositions of the base metals wt $\%$

\begin{tabular}{|c|c|c|c|c|c|c|c|c|}
\hline \hline Alloy & Al & Fe & Mn & Si & Mg & Zn & $\mathbf{C u}$ & $\mathbf{O}_{2}$ \\
\hline AlA & Bal. & - & 0.6 & 1.1 & 0.6 & - & - & - \\
\hline $\mathrm{CP} \mathrm{Cu}$ & - & 0.02 & 0.01 & - & - & 0.01 & Bal. & 0.03 \\
\hline
\end{tabular}

TABLE 2

Tensile strength of base metals at room temperature

\begin{tabular}{|c|c|c|c|}
\hline \hline Alloy & YS (MPa) & UTS (MPa) & El (\%) \\
\hline $\mathrm{AlA}$ & 120.2 & 246.2 & 17.70 \\
\hline $\mathrm{CP} \mathrm{Cu}$ & 173.7 & 269.9 & 18.12 \\
\hline
\end{tabular}

\section{2b. Processing parameters of the welded joints}

From the parent materials, $140 \mathrm{~mm}$ long $\times 60 \mathrm{~mm}$ width samples were machined in such a way that, the two opposite faces of each sample were parallel to each other. A schematic diagram of FSW process and tool dimension is shown in Fig. 1. The high speed steel tool having $25 \mathrm{~mm}$ diameter shoulder with conical pin of $5 \mathrm{~mm}$ diameter and $2.7 \mathrm{~mm}$ height was used for FSW (Fig. 1c). The friction stir welding of $\mathrm{AlA} / \mathrm{Cu}$ were carried out at tool rotational speeds from 300-900 rpm in steps of $150 \mathrm{rpm}$ and travel speed $30 \mathrm{~mm} /$ minutes at constant tool tilt angle $2^{\circ}$. The pin was inserted on the aluminium side at $1 \mathrm{~mm}$ offset.

\section{2c. Microstructure of the welded joints}

For optical microscopy the samples were cut from a transverse section and prepared by conventional metallographic technique. The aluminum alloy and copper sides were etched

with Keller's reagent $\left(1.5 \mathrm{ml} \mathrm{HCl}, 1 \mathrm{ml} \mathrm{HF}, 2.5 \mathrm{ml} \mathrm{HNO}_{3}\right.$ and $95 \mathrm{ml}$ water) and acidified ferric chloride $(50 \mathrm{ml} \mathrm{HCl}, 100 \mathrm{ml}$ $\mathrm{H}_{2} \mathrm{O}$ and $5 \mathrm{gm} \mathrm{FeCl}_{3}$ ) respectively and were observed in a light microscope. Scanning electron microscope (JEOL JSM-7000F) in back scattered mode (SEM-BSE) of the polished surface of the welded sample was done along with chemical analysis by energy dispersive spectroscopy (EDS). The presence of intermetallic phases in the stir zone was confirmed by XRD (Philips PW 1830) using cobalt as target at an operating voltage of $35 \mathrm{kV}$ with a sample current of $25 \mathrm{~mA}$ and scanning range from 20 to $100 \mathrm{deg}$ with step size of $0.01 \mathrm{deg}(=2 \mathrm{~h})$ was used during the study.

\section{2d. Mechanical properties of the welded joints}

Tensile strength of the welded joints was evaluated in a tensile testing machine (Instron 4204) at a crosshead speed of $1.66 \times 10^{-3} \mathrm{~mm} / \mathrm{sec}$ at room temperature. Sub-size tensile specimens with reduced grip dimension were prepared as per ASTM ID: E8M-11, keeping the interface at the centre of the gauge length. Four samples were tested at each process parameter to check the reproducibility of results. The micro-hardness measurement was carried out on the polished surface along the transverse side of the welded samples using a diamond microindenter with a $50 \mathrm{gf}$ load for $20 \mathrm{sec}$ duration.

\section{Results and discussion}

The surface appearance and the macro images of the friction stir welded joints are shown in Fig. 2. From the surface view (Fig. 2a) up to $750 \mathrm{rpm}$ tool rotational speed, surface discontinuity or cavity has not been observed in the welded region; however at $900 \mathrm{rpm}$ tool rotational speed surface discontinuity was present at the stir zone.The surface discontinuity may be attributed to the excessive IMCs formation due to enhanced reaction between $\mathrm{Al}$ and $\mathrm{Cu}$ at higher tool rotational speed [18]. The macrostructure of the FSW joints are shown in Figure $2 b$. Up to $750 \mathrm{rpm}$ tool rotational speed proper mixing occurred without any defect, however at $900 \mathrm{rpm}$ flow of copper was observed on the AlA side.
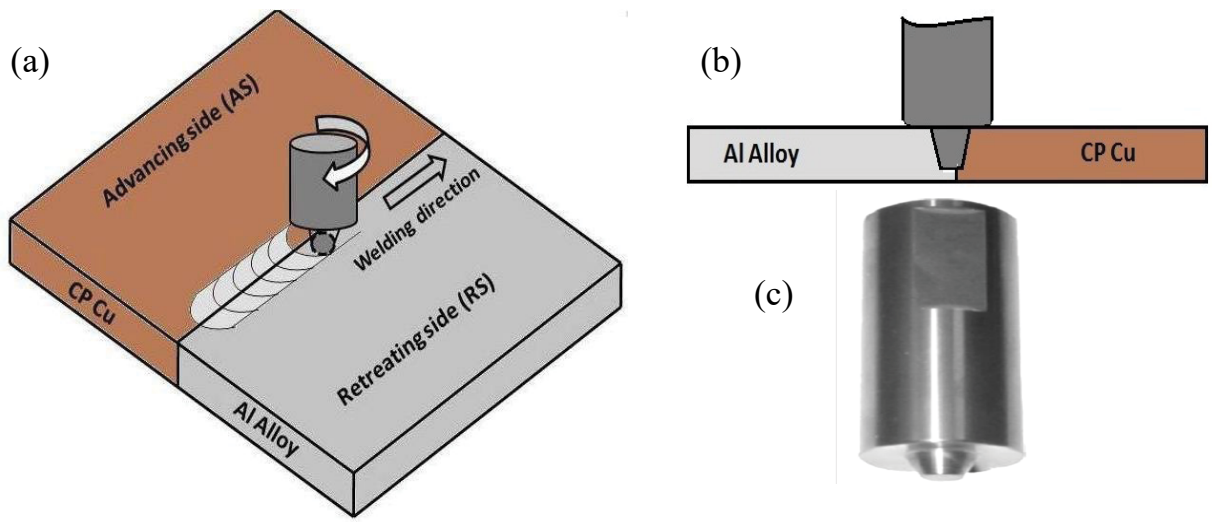

Fig. 1. (a) Schematic diagram of the friction stir welding process, (b) configuration of used tool, (c) design of the tool 


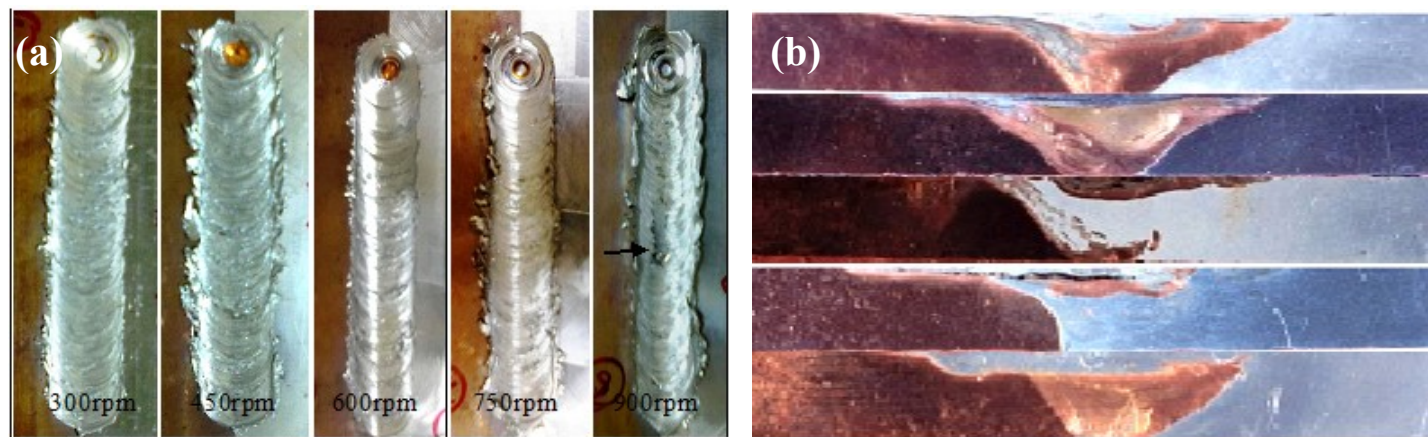

Fig. 2. (a) Surface view of the welded joints (defect marked by arrow), (b) macro structure of the processed at 300-900 rpm
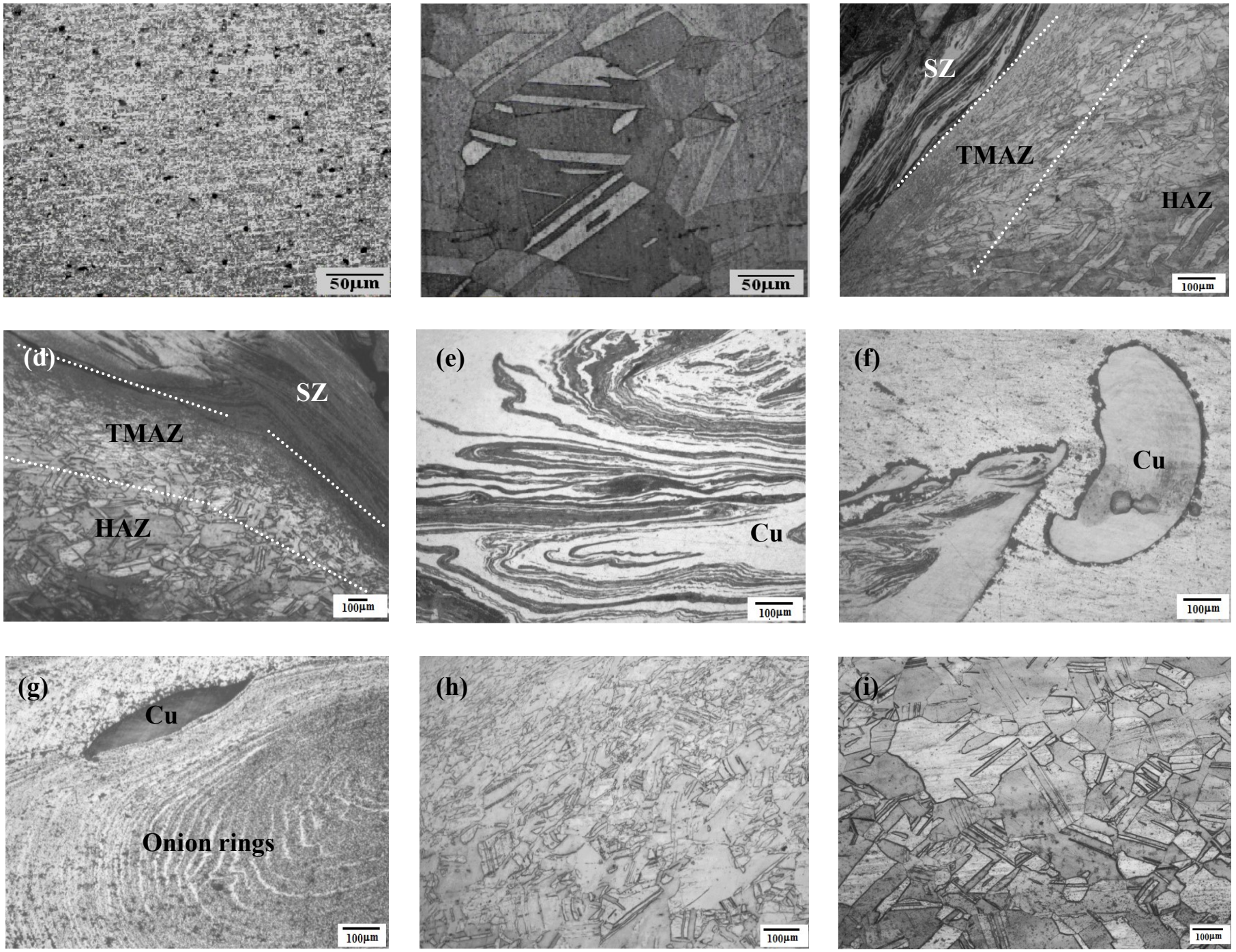

Fig. 3. Optical micrograph of base metals (a) AlA, (b) Cu and FSW joints at $30 \mathrm{~mm} /$ minutes travel speed at: (c) $450 \mathrm{rpm}$, (d) $750 \mathrm{rpm}$, (e) $450 \mathrm{rpm}$ stir zone at the $\mathrm{Cu}$ side, (f) $750 \mathrm{rpm}$ stir zone at the AlA side, (g) $600 \mathrm{rpm}$ stir zone at the AlA side, (h) $750 \mathrm{rpm}$ TMAZ at the Cu side, (i) $450 \mathrm{rpm}$ $\mathrm{HAZ}$ at the $\mathrm{Cu}$ side

The optical microstructures of the FSW joints are shown in Fig. 3. The interface was clearly revealed in the weld joints (Fig. 4c,d). Dispersed copper particles were found distributed within the SZ [19]. The SZ has a structure resembling to that of a copper particle reinforced in AlA (Fig. 3e,f). In the copper side, a metal-flow structure was observed within the interface regions. TMAZ and HAZ have not been observed in the AlA side.
However, that was observed in the copper side (Fig. 3h,i) of FSW joints. The grain sizes at copper side of TMAZ and HAZ of the FSW joints are shown in Fig. 4. It has been found that grain size increased with the tool rotational speed in the both side of SZ region. Higher rotational speed produced the higher temperature due to friction as compared to the lower rotational speed [20]. The fine recrystallized grains in the stirred zone are attributed to 


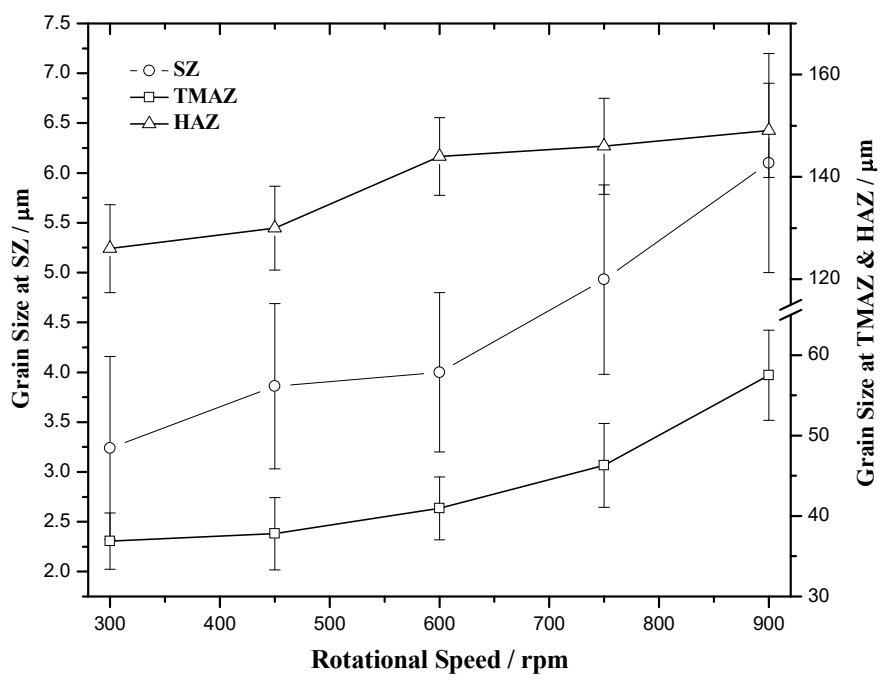

Fig. 4. Grain size changes of the friction stir welded joints at different rotational speed at the copper side

the generation of high deformation and temperature during FSW [21-22]. Cho et al. [23] observed the fine grain microstructure in the SZ and TMAZ region, due to the continuous dynamic recrystallization in FSW joint of high strength line pipe steel.

The SEM-BSE images of AlA-Cu FSW joints are shown in (Figs. 5,6). Up to 750 tool rotational speed no defects were observed in the weld region. However, at $900 \mathrm{rpm}$ cavity was observed at stir zone due to insufficient material flow and forging (arrowed in Fig. 5a). At 300 and 450 rpm, the combination of light and light shaded reactions zone have been observed at the stir region. The concentration of the light shade reaction regions are $\mathrm{Al}(\sim 29.2-34.2$ at \%) and $\mathrm{Cu}(\sim 65.3-69.2$ at \%) with small amounts of Si (0.2-0.5at \%) and Mg (bal.). Hence, the
Al-Cu binary phase diagram indicates the formation of $\mathrm{Al}_{4} \mathrm{Cu}_{9}$ intermetallic compounds [24]. The reaction product has been formed due to the mechanical mixing of copper and Al during FSW. The interface is free from intermetallic compounds up to 450rpm. However, the layer of intermetallics has been observed at the interface when the joint were processed at $600 \mathrm{rpm}$ and above (Fig. 7).

At $600 \mathrm{rpm}$ joint, $\mathrm{Al}_{4} \mathrm{Cu}_{9}$ intermetallic compound has been observed at the interface and the stir region. However, at 750 and $900 \mathrm{rpm}$ layer wise two intermetallic phases have been observed the interface of the joint (Fig.6). At the copper side, the light shaded reaction product is $\mathrm{Al}_{2} \mathrm{Cu}_{3}$ with the composition of $\mathrm{Al}(44.5-46.7$ at $\%)$ and $\mathrm{Cu}(53.9-54.7$ at\%) with small amounts of $\mathrm{Si}(0.2-0.3 \mathrm{at} \%)$ and $\mathrm{Mg}(0.08-0.1 \mathrm{at} \%)$. Next to the $\mathrm{Al}_{2} \mathrm{Cu}_{3}$ phase, another reaction layer consists of $\mathrm{Cu}(49.3-52.6 \mathrm{at} \%)$, $\mathrm{Al}(47.7-50.7 \mathrm{at} \%), \mathrm{Si}(0.3-0.4 \mathrm{at} \%)$ and $\mathrm{Mg}(0.1-0.16$ at $\%)$; hence the composition perhaps is the $\mathrm{AlCu}$ phase [24]. It was also observed that the thickness of the interface reaction layers increases with the increase in tool rotational speed and higher rotational speed generates higher temperature. The width of $\mathrm{Al}_{2} \mathrm{Cu}_{3}$ and $\mathrm{AlCu}$ at the joint interface were 0.5 and $0.6 \mu \mathrm{m}$, respectively at $750 \mathrm{rpm}$ and increased to 1.1 and $0.83 \mu \mathrm{m}$, respectively at $900 \mathrm{rpm}$. At the stir zone, the intermetallic phase $\left(\mathrm{Al}_{4} \mathrm{Cu}_{9}\right)$ and the free $\mathrm{Cu}$ were dispersed in the AlA matrix (Fig. 5b,d,e). It was also observed that the volume fraction of the intermetallic phases increases with the increase in the tool rotational speed. Galvao et al. investigated that $\mathrm{Al}_{4} \mathrm{Cu}_{9}$ and $\mathrm{Al}_{2} \mathrm{Cu}$ were identified in the $\mathrm{x}$-ray diffraction pattern in the dissimilar friction stir lap welded joint between aluminium and copper [25]. Tan et al. [19] reports that the layer of $\mathrm{Al}_{4} \mathrm{Cu}_{9}, \mathrm{Al}_{2} \mathrm{Cu}_{3}$ and $\mathrm{Al}_{2} \mathrm{Cu}$ intermetallic phases were identified in TEM in the dissimilar $\mathrm{Al}$ and $\mathrm{Cu}$ FSW joint.
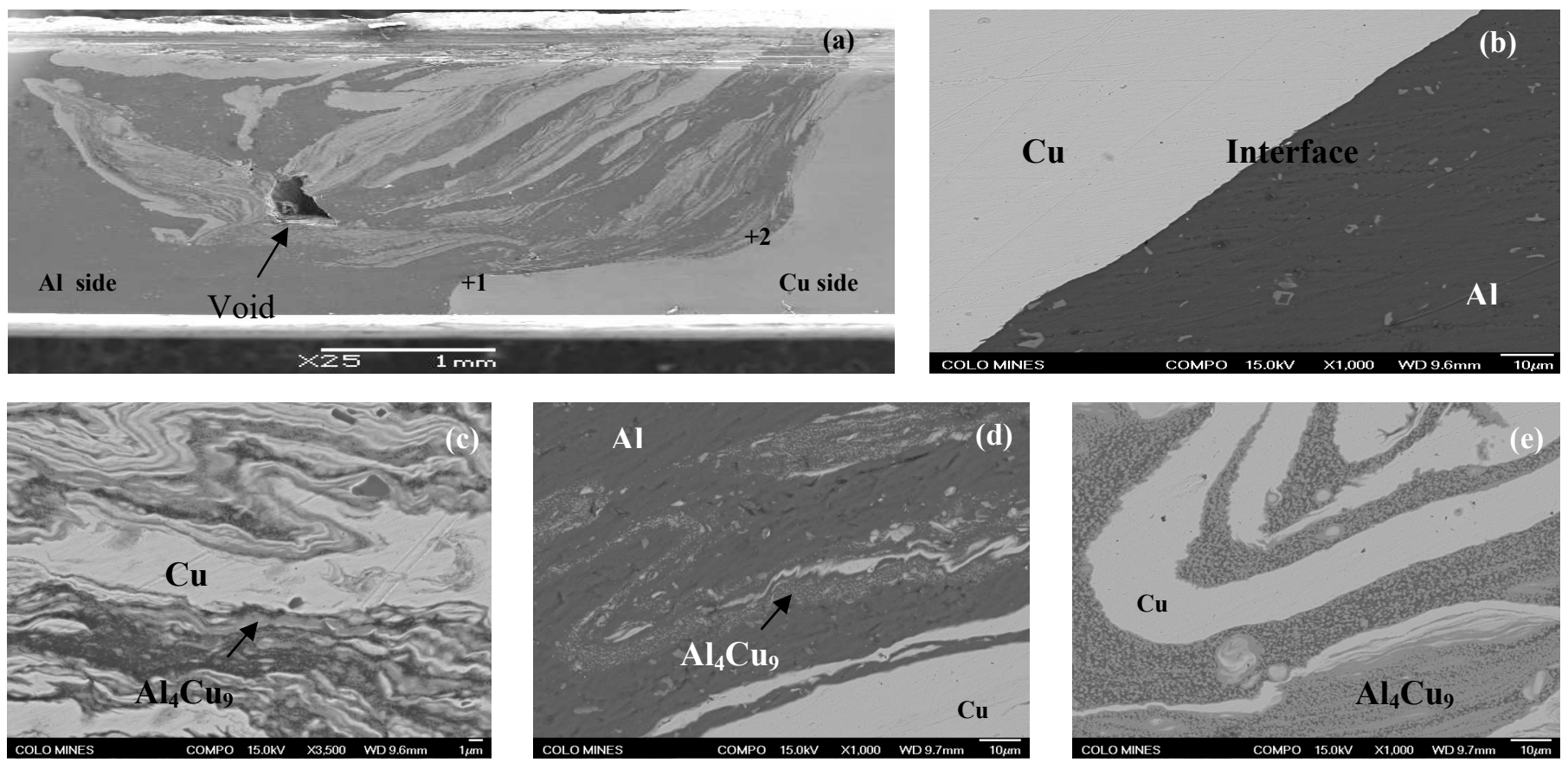

Fig. 5. SEM-BSE images of FSW joints at $30 \mathrm{~mm} /$ minutes travel speed at (a) $900 \mathrm{rpm}$ full view, (b) $300 \mathrm{rpm}$ interface of the Cu-AlA, (c) stir zone at $300 \mathrm{rpm}$, (d) $450 \mathrm{rpm}$ interface of Cu-AlA, (e) stir zone of $450 \mathrm{rpm}$ 

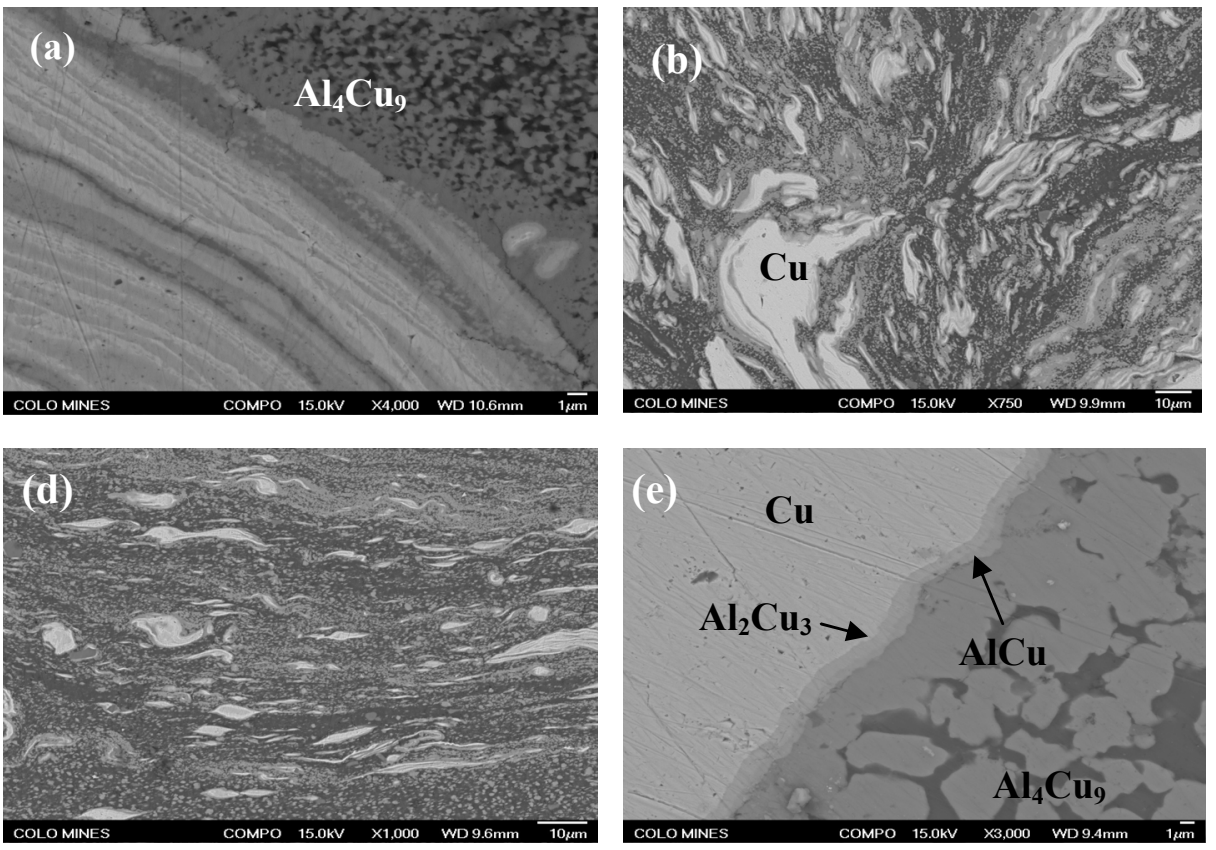

Fig. 6. SEM-BSE images of FSW joints at $30 \mathrm{~mm} /$ minutes travel speed at (a) $600 \mathrm{rpm}$ interface of the Cu-AlA, (b) stir zone at $600 \mathrm{rpm}$, (c) $750 \mathrm{rpm}$ interface of the Cu-AlA, (d) stir zone at $750 \mathrm{rpm}$, (e) $900 \mathrm{rpm}$ interface of the Cu-AlA, (f) stir zone of $900 \mathrm{rpm}$

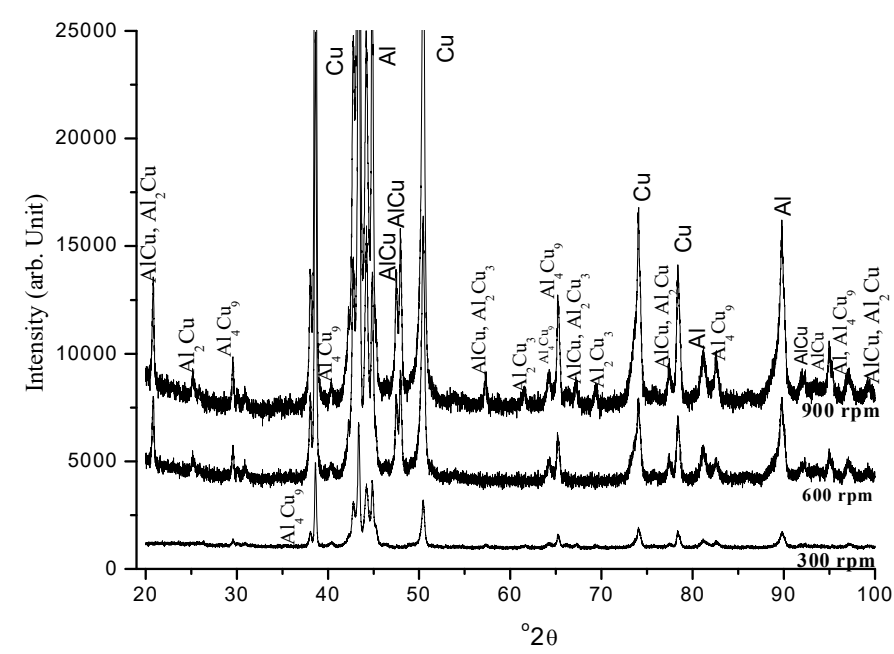

Fig. 7. X-ray diffraction pattern of the FSW joints samples

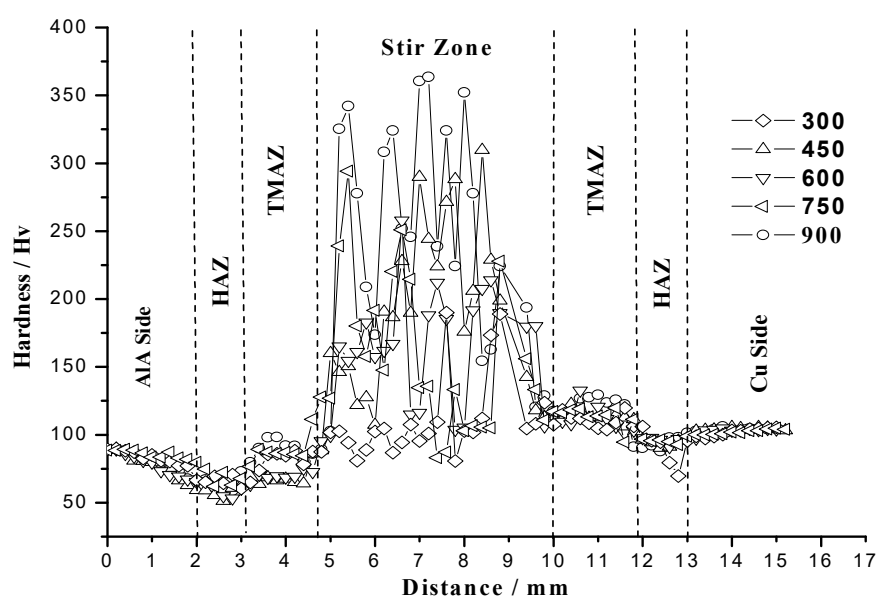

Fig. 9. Micro-hardness profile of the FSW joint for varying rotational speed

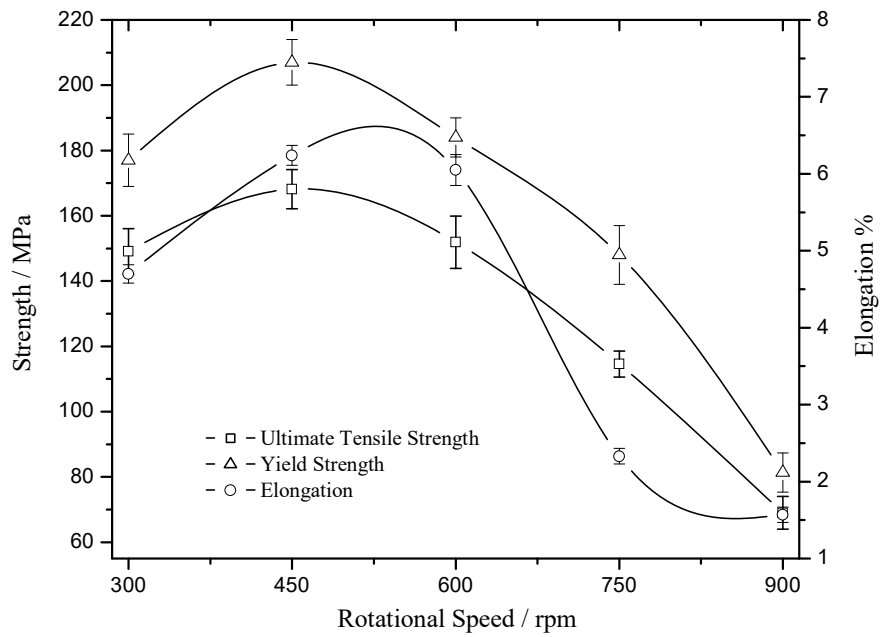

Fig. 8. Tensile strength of the FSW samples of different rotational speeds

The x-ray diffraction patterns of the FSW joints with varying tool rotating speed were shown in Fig. 7. At the lower rotational speed up to $600 \mathrm{rpm}$, the characteristic diffraction peaks of only $\mathrm{Al}_{4} \mathrm{Cu}_{9}$ intermetallics phase has been identified, which indicates the presence of $\mathrm{Al}_{4} \mathrm{Cu}_{9}$ in the stir zone. However, at the higher rotation rate of $750 \mathrm{rpm}$ and above, characteristic peaks of $\mathrm{AlCu}, \mathrm{Al}_{2} \mathrm{Cu}_{3}$ and $\mathrm{Al}_{4} \mathrm{Cu}_{9}$ intermetallics phases were observed.

The tensile strength of the FSW joints with the change in tool rotational speeds is shown in Fig. 8. At low tool rotating speed of $300 \mathrm{rpm}$, the tensile strength UTS and YS and elongation are lower due to void present in the stir zone (Marked in Fig. 5a). A tool rotation speed of $450 \mathrm{rpm}$ made a good joint, showing the maximum UTS and YS of $\sim 207 \mathrm{MPa}$ and $\sim 168 \mathrm{MPa}$, respectively, and along with $\sim 6.2 \%$ elongation at fracture. 
With an increase in the tool rotational speed, the weld strength decreases gradually due to the increase in the volume fraction of intermetallics and weld strength attains the lowest tensile strength (UTS of $\sim 81 \mathrm{MPa}$ and YS of $\sim 69 \mathrm{MPa}$ ) along with $\sim 1.6 \%$ elongation at fracture, when welding was carried out at $900 \mathrm{rpm}$ tool rotational speed. At higher rotational speed, higher temperature was produced at the weld interface and promotes the mechanical mixing of the elements, which is responsible for the increase in volume fraction of reaction products; hence, this causes more embrittlement of the joints. Tan et al. [19] reports the maximum tensile strength was obtained $\sim 130 \mathrm{MPa}$ for the FSW of 5A02 aluminum alloy and pure copper at $1100 \mathrm{rpm}$ and $20 \mathrm{~mm} / \mathrm{min}$ rotational and traverse speeds, respectively. Xue et al. [14] reports that maximum tensile strength achieved of $\sim 110 \mathrm{MPa}$ for of $\mathrm{Cu}-1060 \mathrm{Al}$ dissimilar joints, when processed at $600 \mathrm{rpm}$ rotational speed and a constant traverse speed of $100 \mathrm{~mm} / \mathrm{min}$. The UTS and YS values exhibits a substantial improvement in welding quality with respect to Tan et al. [19] and Xue et al. [14] reported values.

Microhardness profiles for all joints along the transverse cross-section are shown in Fig. 9. The hardness values of the TMAZ ranges between 105.4 -129.3 HV and HAZ ranges between 90.3-98.9 HV on copper side. However, at the Al-side the hardness of the TMAZ ranges between 64.4-98.3 HV and in HAZ ranges between 53.2-74.8 HV. In the stir zone hardness values varies between $80.7-363.5 \mathrm{HV}$. At the stir zone region the hardness values varies widely due to the presence of intermetallics embedded in the base materials.

Fig. 10 shows the SEM morphologies of fracture surfaces of FSW joints at different tool rotating speeds. From samples produce at lower tool rotating speed up to $450 \mathrm{rpm}$ were characterized by dimples in different sizes. However, at $600 \mathrm{rpm}$ joints shows that the some of the area are smooth surface without severely deformed. At 750 and $900 \mathrm{rpm}$, fracture surface clearly indicates the brittle nature of the joint by the presence of cleavage planes with different alignments. The ductile fracture has indicated the higher strength and elongation of the FSWed joint than the brittle fracture.

\section{Summary and conclusions}

In the present study, the friction stir welding between AlA and commercially pure copper was carried out in the range of tool rotational speed of 300-900 rpm in steps of $150 \mathrm{rpm}$ at 30 $\mathrm{mm} /$ minutes travel speed. In the optical microstructure, the HAZ and TMAZ were clearly visible on the $\mathrm{Cu}$ side, while in the AlA side, HAZ and TMAZ were not clearly distinguishable. The grain size of TMAZ and HAZ at the $\mathrm{Cu}$ side increased with the increase in tool rotational speeds. In the stir zone, shaded and light shaded combination has been observed. The interface free from intermetallics and $\mathrm{Al}_{4} \mathrm{Cu}_{9}$ intermetallics has been observed at the stir zone for the joints processed up to $450 \mathrm{rpm}$. However, $\mathrm{Al}_{4} \mathrm{Cu}_{9}$ intermetallics was observed at the interface and the stir zone at $600 \mathrm{rpm}$. At 750 and $900 \mathrm{rpm}$ tool rotational speeds, the layers of $\mathrm{AlCu}, \mathrm{Al}_{2} \mathrm{Cu}_{3}$ and $\mathrm{Al}_{4} \mathrm{Cu}_{9}$ intermetallics were observed at the interface and only $\mathrm{Al}_{4} \mathrm{Cu}_{9}$ intermetallics has been observed in the stir zone. The presences of these intermetallics were confirmed by $\mathrm{x}$-ray diffraction technique. The maximum ultimate tensile strength of $\sim 207 \mathrm{MPa}$ and yield strength of $\sim 168 \mathrm{MPa}$ along with $\sim 6.2 \%$ elongation at fracture of the joint have been obtained when processed at $450 \mathrm{rpm}$ tool rotational speed. Fracture surface observed that at lower rotational speed up to $450 \mathrm{rpm}$ fracture surfaces were ductile in nature and at high rotational speed at $750 \mathrm{rpm}$ and above fracture surface were brittle in nature.
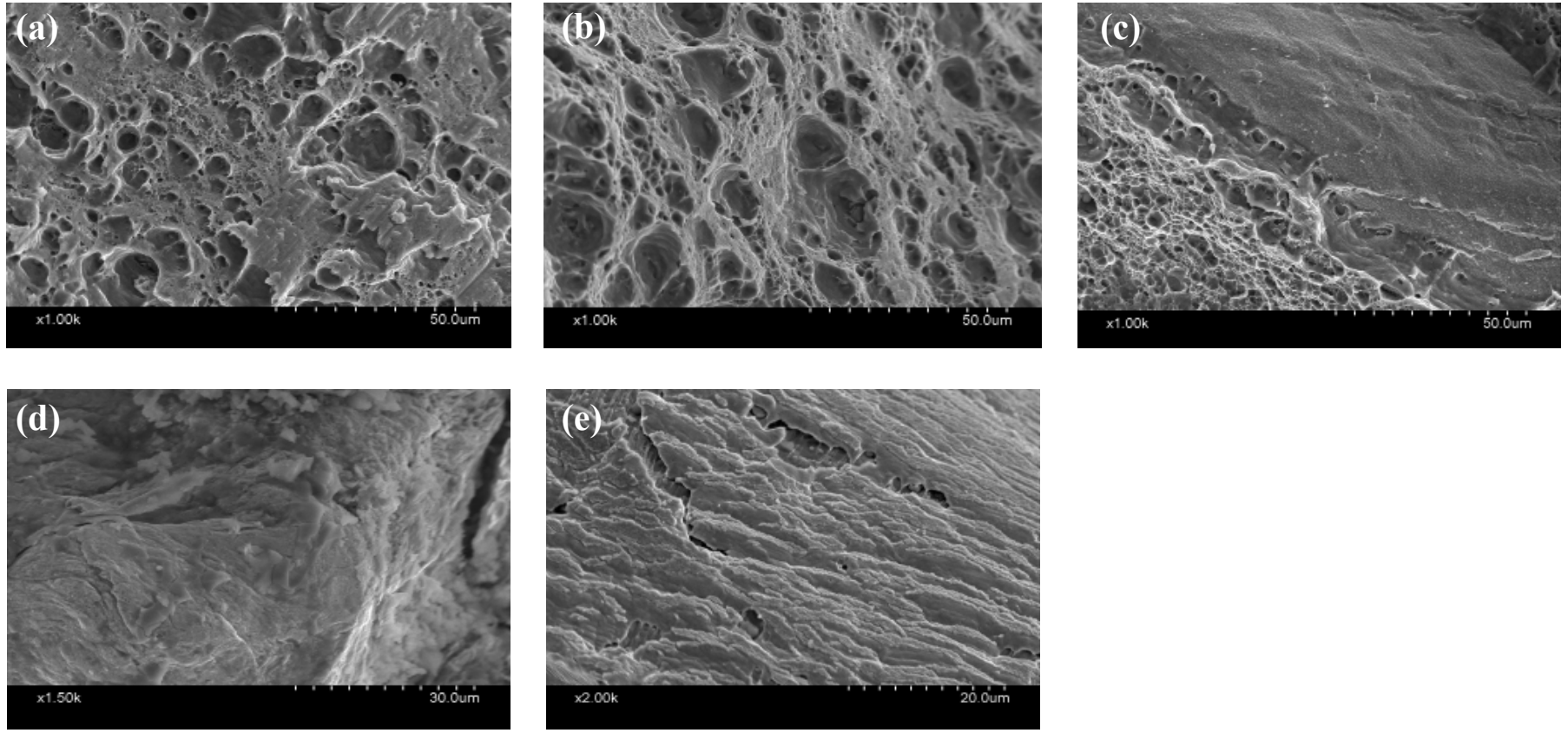

Fig. 10. Fracture surfaces of FSW joints at the rotating speed of (a) $300 \mathrm{rpm}$, (b) $450 \mathrm{rpm}$, (c) $600 \mathrm{rpm}$, (d) $750 \mathrm{rpm}$, (e) $900 \mathrm{rpm}$ 


\section{REFERENCES}

[1] R.S. Mishra, Z.Y. Ma, Mat. Sci. Eng. R50, 1-78 (2005).

[2] W.B. Lee, M. Schmuecker, U. Mercardo, G. Biallas, S. Jung, Scripta Mater. 55 (4), 355-358 (2003).

[3] Y.S. Sato, Y. Kurihara, S.H.C. Park, H. Kokawa, N. Tsuji, Scripta Mater. 50, 1233-1237 (2004).

[4] J. Yan, Z.Xu, Z.Li, L.Li, S.Yang, Zongshan Li, Scripta Mater. 53, 585-589 (2005).

[5] M. Wig, F. Albert, M. Schmidt, Phy. Proc. 12, 335-341 (2011).

[6] P. Liu, Y.Q. Shi, W. Wang, X. Wang, Z.L. Zhang, Mater. Let. 62, 4106-4108 (2008).

[7] J.H. Ouyang, E. Yarrapareddy, R. Kovacevic, J. Mater. Proc. Techn. 172,110-122 (2006).

[8] R.N. An, T. Debroy, H. Bhadeshia, Prog. Mater. Sci. 53, 980-1023 (2008).

[9] A.C. Somasekharan, L.E. Murr, J. Mater. Sci. 41, 5365-5370 (2006).

[10] T. Tsutomu, M. Taiki, H. Tomotake, Scripta Mater. 61,756-759 (2009).

[11] A. Kostka, R.S. Coelho, J. dos Santos, A.R. Pyzalla, Scripta Mater. 60, 953-956 (2009).

[12] Y.C. Chen, K. Nakata, Mater. Des. 30, 469-474 (2009).

[13] A. Elrefaey, M.Takahashi, K. Ikeuchi, Proc. PSEA 04-14th Iketani Conference, 507-512, Kyoto 2004.
[14] P. Xue, D.R. Ni, D. Wang, B.L. Xiao, Z.Y. Ma, Mater. Sci. Eng. 528,4683-4689 (2011).

[15] X.W. Li, D. Zhang, C. Qiu, W. Zhang, Trans. Nonferrous Met. Soc. China 22, 1298-1306 (2012).

[16] T. Saeid, A. Abdollah-Zadeh, B. Sazgari, J. Alloy Compd. 490, 652-655 (2010).

[17] A. Abdollah-Zadeh, T. Saeid, B. Sazgari, J. Alloy Compd. 460, 535-538 (2008).

[18] V. Firouzdor, S. Kou, Metall. Mater. Trans. A 43 (1), 303-15(2012).

[19] C.W. Tan, Z.G. Jiang, L.Q. Li, Y.B. Chen, X.Y. Chen, Mater. Design 51, 466-473 (2013).

[20] T. Watanabe, H. Takayama, A. Yanagisawa, J. Mater. Proc. Technol. 178, 342-349 (2006).

[21] C. Uzun, C.D. Donne, A. Argagnotto, T. Ghidini, C. Gambaro, Mater. Des. 26,41 (2005).

[22] H.S. Park, T. Kimura, T. Murakami, Y. Nagano, K. Nakata, M. Ushio, Mater. Sci. Eng. A 371,160-169 (2004).

[23] H.H. Cho, S. H. Kang, S.H. Kim, K.H. Oh, W.S. Chang, H.N. Han, Mater. Des. 34, 258-267 (2012).

[24] T.B. Massalski, Materials Park-OH, ASM International 1996, $2^{\text {nd }}$ edn., 1783.

[25] I. Galvao, D. Verdera, D. Gesto, A. Loureiro, D.M. Rodrigues, J. Mater. Proc. Tech. 213, 1920-1928 (2013). 